\title{
RELACIONAMENTOS ENTRE AS ESPÉCIES AUTÓGAMAS DE CUPHEA P. BROWNE SEÇÃO BRACHYANDRA KOEHNE (LYTHRACEAE)
}

\author{
Shirley A. Graham ${ }^{\prime}$
}

\section{Recebido em 28/11/1997. Aceito em 26/10/1998}

\begin{abstract}
RESUMO - (Relacionamentos entre as espécies autógamas de Cuphea P. Browne seção Brachyandra (Lythraceae)). A seção Brachỵandra, uma das 13 seções de Cuphea, é excepcional por compreender a maioria das espécies autógamas do gênero. A maior parte das outras espécies de Cuphea, embora autocompatíveis, são alógamas protândricas. A seção Brachỵandra é definida pela presença de estames com filetes curtos e profundamente inseridos no tubo floral. caracteres diretamente relacionados à autogamia. Entre as espécies da seção, existem poucas diferenças na morfologia floral e os caracteres vegetativos são variáveis e sobrepostos. As similaridades poderiam ser atribuídas à recente especiação dentro de um grupo monofilético, definido pela aquisição do modo autógamo de reprodução, ou a seção poderia ser polifilética, com similaridades resultantes de convergência, dirigidas pela mudança de alógamas para autógamas. A morfologia do pólen e da semente, descrita agora para este grupo, sugere que a seção Brachỵandra não seja monofilética, mas sim que compreenda um mínimo de três diferentes linhas evolutivas, representadas por: 1) quatro espécies com sementes aladas e pólen oblato, sincolporado e estriado. com poros proeminentes; 2) duas espécies com sementes grandes e não aladas e pólen psilado, sem poros proeminentes e leves espessamentos interaperturados; 3 ) oito espécies com sementes pequenas, não aladas e quase esferoidais, pólen não sincolpado, psilado a rugulado. $\mathrm{A}$ variação neste último grupo sugere que o mesmo seja derivado de mais do que um ancestral. Na análise cladística, as espécies da seção Brachyandra ocorrem dentro de clados de espécies das seçōes Euandra, Pseudocircaea, Trispermum e Amazoniana. Os resultados indicam que não existe base filogenética sólida para o reconhecimento da seção Brachỵandra como presentemente definida.
\end{abstract}

Palavras-chave - Lythraceae, Cuphea, Brachyandra. espécies autógamas, cladística

\begin{abstract}
Relationships among autogamous species of Cuphea P. Browne section Brachyandra (Lythraceae)). Section Brachyandra, one of 13 sections of Cuphea. is exceptional in comprising the majority of self-fertilizing species in the genus; most other Cuphea, although self-compatible, are protandrous outcrossers. The section is defined by presence of stamens with short filaments deeply inserted in the floral tube. characters directly tied to autogamy. There are few differences in floral morphology among the species and vegetative features are variable and overlapping. The close similarities may be attributed to recent speciation within a monophyletic group that is defined by the acquisition of this reproductive mode, or the section may be polyphyletic, with the similarities the results of convergence driven by the change from outcrossing to selfing. Seed and pollen morphology, previously undescribed in this group, suggest that sect. Brachyandra is not monophyletic but comprises a minimum of three different evolutionary lines: 1) four species with winged seeds and oblate, syncolporate, striated pollen with protruding pores; 2 ) two species with large non-winged seeds and psilate pollen without protruding pores and with slight interaperturate thickenings; 3 ) eight species with small non-winged seeds and nearly spheroidal, non-syncolporate, psilate to rugulate
\end{abstract}

' Departamento de Ciências Biológicas, Kent State University. Kent. OH 44242, EUA 
pollen. Variation in the last group suggests it is derived from more than one ancestor. In cladistic analysis, the species of section Brachyandra occur within clades of species from sections Euandra. Pseudocircaea, Trispermum, and Amazoniana. Results indicate that there is no sound phylogenetic basis for continued recognition of sect. Brachyandra as it is presently defined.

Key words - Lythraceac, Cuphea, Brachyandra, self-fertilizing species, cladistic analyses

\section{Introdução}

Cuphea é o maior gênero das Lythraceae, com cerca de 250 espécies classificadas em 13 seções (Graham 1988). Cerca de 18 espécies constituem a seção Brachyandra, que é basicamente definida pela presença de estames com filetes muito curtos e profundamente inseridos no tubo floral (Koehne 1903) (Fig. 1). As flores das espécies desta seção estão entre as menores do gênero, a maioria com 4-6mm de compr., com tubo floral quase regular, verde a purpúreo e seis pétalas de igual tamanho. Com relação ao aspecto vegetativo, as plantas apresentam-se como pequenas ervas, compartilhando habitats similares, e com folhas de morfologia bastante variável. A interpretação desta variabilidade tem levado ao aumento do número de espécies na seção e também ao reconhecimento de uma série de subespécies e variedades. As espécies da seção distribuem-se através dos neotrópicos, com sete a nove espécies ocorrendo no Brasil (quatro endêmicas): Cuphea aperta Koehne, C. calophylla Cham. \& Schldl., C. carthagenensis (Jacq.) Macbr., C. circaeoides Smith, C. fuscinervis Koehne, C. micrantha H. B. K., C. repens Koehne e C. tenuissima Koehne. A seção é também bem representada nas Antilhas por cerca de nove espécies (seis endêmicas). Simpatria de duas a ocasionalmente três espécies com o mesmo tipo de habitat e morfologia floral, tem levado a resultados confusos em levantamentos florísticos e à muitas coleções identificadas incorretamente.

As características florais que definem a seção estão relacionadas ao modo autógamo de reprodução. Tubos florais pequenos, estames que não alcançam a margem do tubo floral, com anteras profundamente inseridas no tubo, que às vezes se abrem precocemente, e estigma posicionado no mesmo nível ou abaixo das anteras indicam baixa probabilidade para a introdução de pólen de flores de outras plantas ou de pólen de outras flores da mesma planta. (Weberling 1989). A autofecundação foi verificada experimentalmente em seis espécies da seção Brachyandra (Cuphea calophylla, C. carthagenensis, C. elliptica, C. melanium, C. micrantha e $C$. parsonsia) (Graham, não publicado).

A morfologia floral na seção Brachyandra contrasta fortemente com aquela encontrada nas espécies com flores grandes e mais zigomórficas do gênero, de seções tais como Melvilla e Diploptychia. As espécies de flores grandes destas seções (15-35mm compr.), bem como as espécies mais comuns pertencentes a outras seções do gênero, com seus tubos florais de tamanhos moderados (7-15mm compr.), são alógamas e protândricas; os estames e o estilete sobressaem do tubo floral e estão posicionados para o recebimento e liberação de pólen, através de insetos visitantes de probóscide longa.

Pelo menos duas hipóteses podem ser lançadas para explicar as similaridades da morfologia floral entre as espécies da seção Brachỵandra. Em uma hipótese, as similaridades são atribuídas à especiação recente dentro de um grupo monofilético. $\mathrm{O}$ 


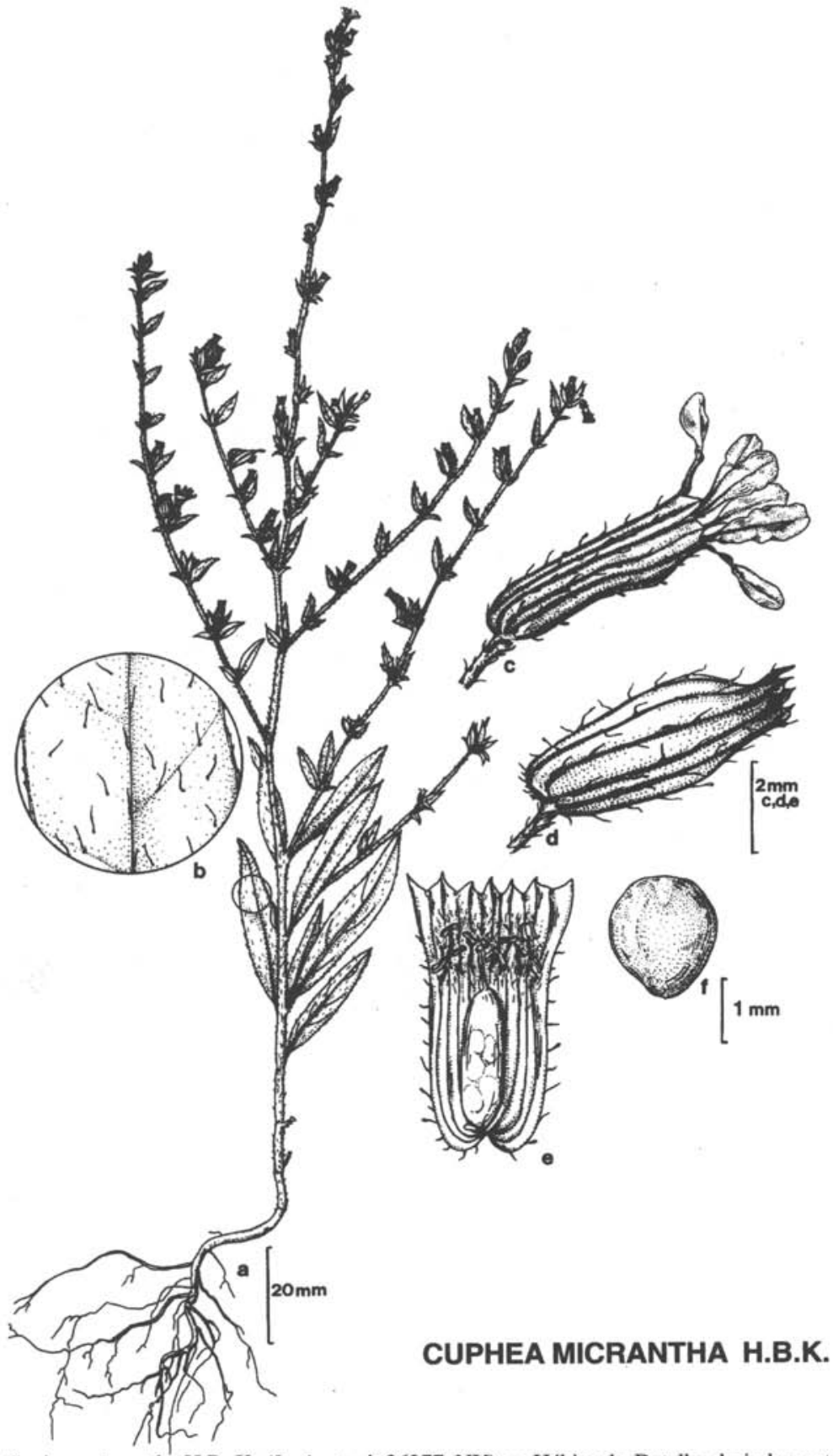

Figura 1. Cuphea micrantha H.B. K. (Irwin et al. 26277, NY). a. Hábito; b. Detalhe do indumento da face adaxial da folha, tricomas = $1 \mathrm{~mm}$; $c$. flor; $d$. tubo floral na frutificação; e. tubo floral em corte longitudinaldorsal, mostrando pistilo com disco nectarífero basal e estames; f. semente não alada. 
grupo seria definido pela aquisição do modo autógamo de reprodução. $\mathrm{Na}$ segunda hipótese, similaridades seriam devido à convergência nos caracteres florais, como resultado de mudanças evolutivas, de alógamas para autógamas, resultando em uma seção polifilética. Para investigar a filogenia da seção Brachyandra e estimar a frequiência do aparecimento da autofecundação no gênero, analisou-se características ainda não estudadas no grupo e não diretamente relacionadas à biologia reprodutiva. Dois conjuntos de caracteres, morfologia da semente e do pólen, mostraram ser altamente informativos fornecendo as bases para a reconstrução da filogenia da seção Brachyandra e clarificar as linhas evolutivas da autogamia entre os seus membros.

\section{Material e métodos}

Amostras de sementes e de pólen, de 14 das aproximadamente 18 espécies, foram utilizados para o estudo. Coleções vivas cultivadas nas casas de vegetação da Universidade de Kent forneceram as sementes e pólen para os estudos com microscopia eletrônica de varredura (MEV) e microscopia óptica (MO), para todas as espécies, exceto Cuphea rusbyi, C. repens e C. circaeoides, cujo material foi estudado a partir de espécimes de herbário.

Todas as coleções vivas possuem "vouchers" em herbários, conforme indicado nas legendas das figuras. As amostras de pólen foram processadas pelo método padrão de acetólise de Erdtman (1960). O pólen sobrenadante em álcool etílico 30\% foi montado em "stubs" de alumínio. Para os estudos de MEV, os pólen e as sementes secas, não tratadas, sofreram cobertura com ouro-paládio, com espessura de $400 \AA$.

As análises cladísticas foram realizadas utilizando PAUP Vers. 3.1 (Swofford 1993) em computador MacIntosh Power PC. A análise inicial com PAUP empregou a opção de busca heurística, com adição simples de taxa, "tree-bisection-reconnection branch-swapping" (TRB), MULPARS que salva todas as árvores igualmente mais parcimoniosas, e "steepest descent turned on", como maneira de encontrar todos os grupos de árvores. A evolução de caracteres foi investigada usando MacClade, Vers. 3 (Maddison \& Maddison 1992).

\section{Resultados e discussão}

Morfologia da semente - A morfologia da semente foi extensivamente utilizada por Koehne (1903) na elaboração da classificação infragenérica de Cuphea, embora não tenha sido usada para a seção Brachyandra. Diferentes formas de sementes, tamanhos e formatos de margem provêem a base primária para o reconhecimento de subseções na seção Euandra, seção considerada por Koehne (1903) a mais similar à seção Brachyandra. A seção Brachyandra, ao ser analisada em relação a estes aspectos, apresentou excepcional diversidade de tipos (Fig. 2). Dois tipos básicos de sementes ocorrem nas espécies estudadas: 1) sementes aladas (quatro espécies) - Cuphea carthagenensis, C. elliptica, C. parsonsia e $C$. rusbyi. 2) sementes não aladas (dez espécies). As sementes não aladas incluem três variações: i) sementes com a testa tuberculada - $C$. circaeoides; ii) sementes muito pequenas, com a testa frouxamente aderida - $C$. repens; e iii) sementes com testa foveolada - C. calophylla, C. ciliata, C. melanium, C. urens, C. pseudosilene, C. micrantha 


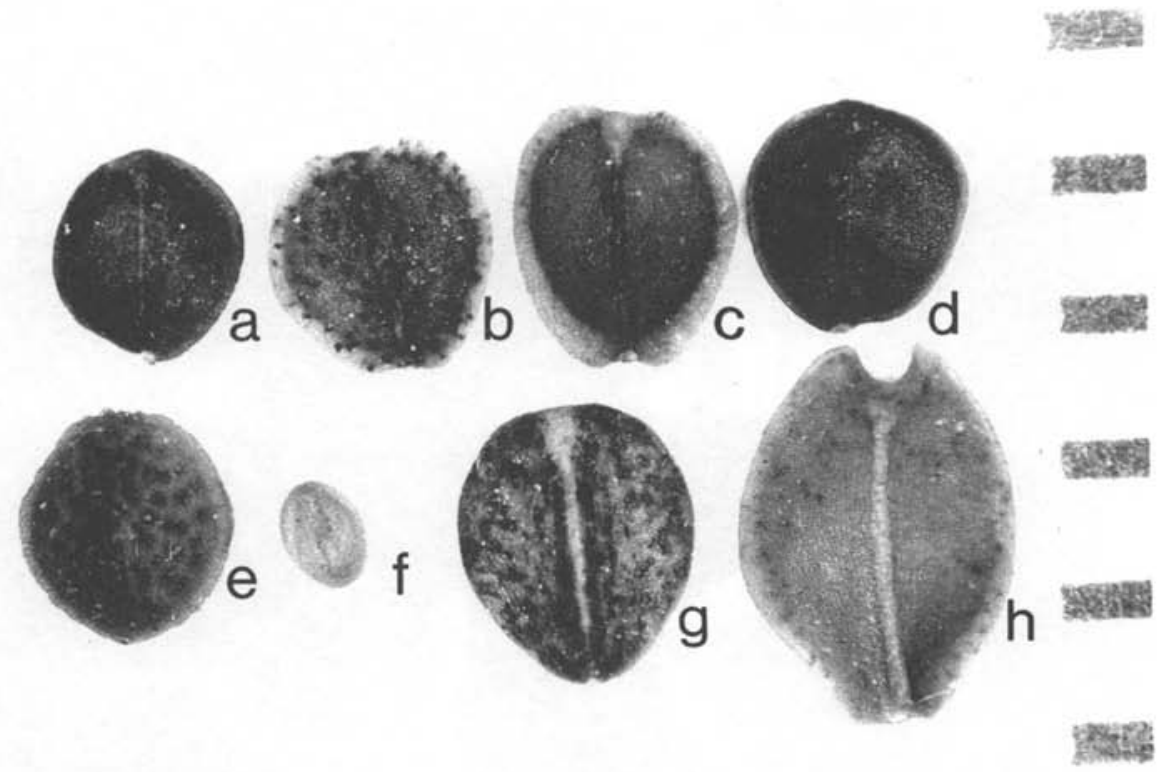

Figura 2. Sementes de oito espécies de Cuphea Seção Brachyandra. a. C. melanium (Ekman 1201, US); b. C. parsonsia (Ekman 872, S); c. C. carthagenensis (Argeñal 31, UNAH); d. C. calophylla (Graham 923, KEG); e. C. circaeoides (Mori et al. 9967, NY); f. C. repens (Irwin et al. 17004, MO); g. C. micrantha (Cavalcante $150289, \mathrm{KE}-\mathrm{G})$; h. C. rusbyi (Rusby 117a, US). Escala em mm.

e C. tenuissima. Exceto pelas sementes de C. repens, de 0,6-0,7 mm compr., a variação de comprimento nas outras espécies está entre 1,5-3,0 $\mathrm{mm}$. Cuphea micrantha e C. tenuissima possuem sementes muito similares, cordiformes e quase nos limites máximos da variação, de 1,9-2,3mm compr. Duas espécies freqüentemente confundidas nas Antilhas, $C$. parsonsia e $C$. melanium, podem ser facilmente separadas com base nas sementes aladas versus não aladas (Fig. 2).

Morfologia do pólen - A segunda fonte de informação abordada neste estudo é a morfologia do pólen que, como nas sementes, contém diversidade de tipos dentro da seção. A diversidade do pólen na seção Brachyandra é maior do que freqüentemente visto num gênero inteiro. Quatro tipos são reconhecidos (Fig. 3a-d): 1) Pólen ovaltriangular, estriado, sincolpado, com poros proeminentes - cinco espécies $(C$. carthagenensis, C. parsonsia, C. elliptica, C. rusbyi, C. pseudosilene). 2) Pólen esferoidal, grãos pequenos, psilados a rugulados, não-sincolpados, poros não proeminentes - seis espécies (C. calophylla, C. ciliata, C. circaeoides, C. melanium, C. riparia, C. urens). 3) Pólen oval-triangular, psilado, sincolpado, poros levemente proeminentes e em MO, as paredes entre os poros levemente espessadas - duas espécies (C. micrantha, C. tenuissima). 4) Pólen triangular, psilado, sincolpado, poros não proeminentes - uma espécie (C. repens). Quando os caracteres da semente e do pólen são comparados, distintos relacionamentos são percebidos. Sementes aladas ocorrem com o pólen estriado, do tipo 1 - quatro espécies (C. carthagenensis, C. elliptica, C. parsonsia, C. rusbyi; uma exceção é C. pseudosilene, 


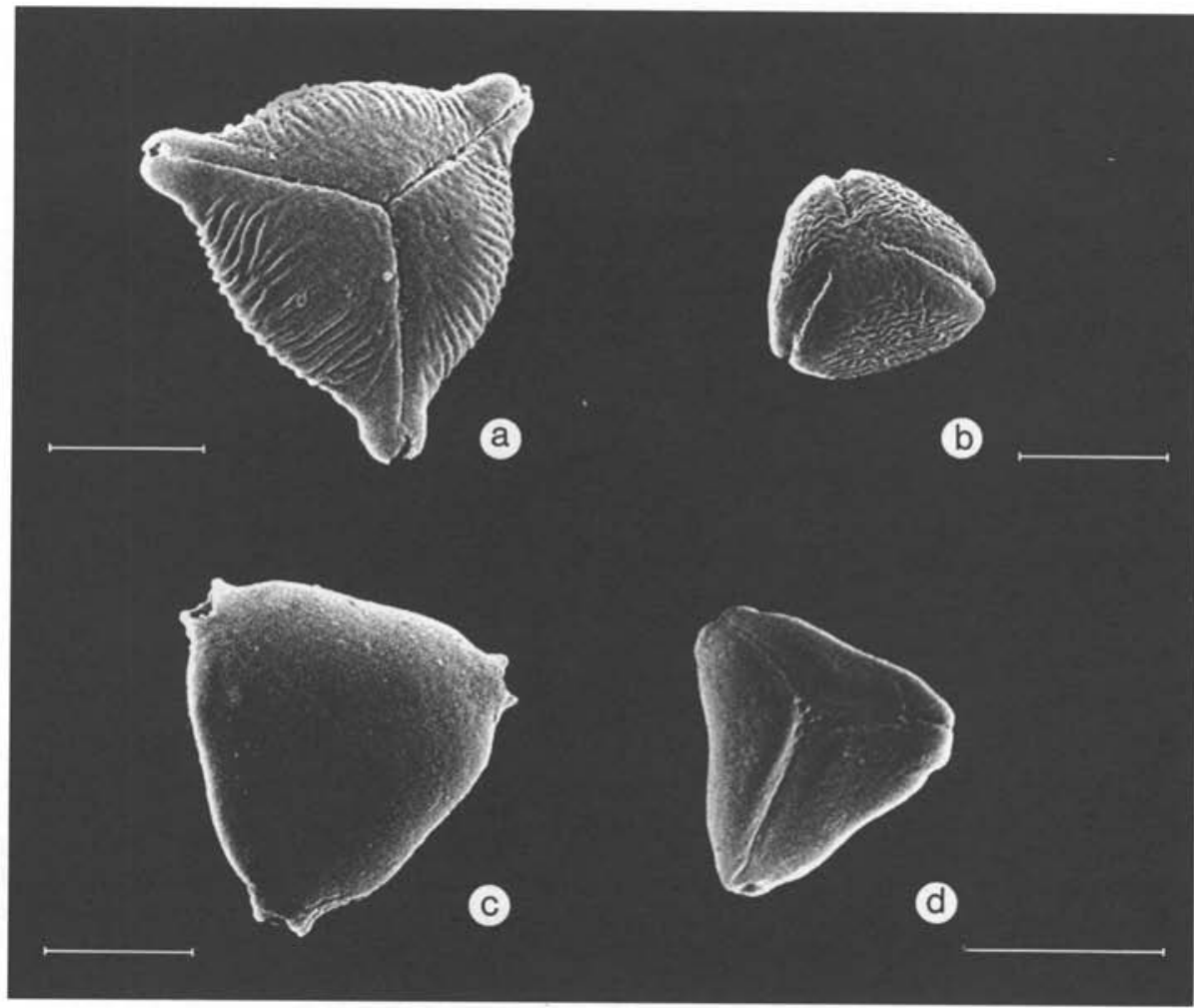

Figura 3. Tipos de pólen em Cuphea seção Brachyandra (MEV). a. C. pseudosilene (Killip 44140, MO); b. C. riparia (Ekman 10242, A); c. C. micrantha (Irwin et al. 19080, NY); d. C. repens (Ferreira et al. 6078, NY). $($ Escalas $=10 \mu \mathrm{m})$.

que possui sementes não aladas mas pólen estriado) (Fig. 4 a-f). Sementes não aladas ocorrem com o tipo 2 de pólen psilado e não sincolpado - seis espécies (C. calophylla, $C$. ciliata, C. melanium, C. urens, C. riparia). (Fig. 5 a-f). Sementes não aladas, grandes e cordiformes ocorrem com o pólen do tipo 3, psilado, com paredes espessas - duas espécies (C. micrantha e C. tenuissima) (Fig. 6 a, b). Sementes não aladas, pequenas, com testa pouco aderida, ocorrem com o pólen do tipo 4 , triangular e psilado - uma espécie ( $C$. repens) (Fig. 6 c, d).

Análise cladística - A análise cladística foi efetuada para testar as hipóteses postuladas para a filogenia da seção Brachyandra e a evolução da autofecundação entre as espécies. O total de 27 táxons foram utilizados. quatorze espécies da seção Brachyandra, 11 espécies de quatro seções relacionadas, e dois táxons como grupos externos, o gênero Pleurophora e $C$. utriculosa da seção Cuphea, para polarizar os caracteres escolhidos. Vinte e sete caracteres morfológicos, não diretamente relacionados à autofecundação, foram utilizados (Tab. 1 e 2). A busca encontrou 370 árvores mais parcimoniosas com um comprimento de árvore (t.1.) de 72, índice de consistência (ci) 


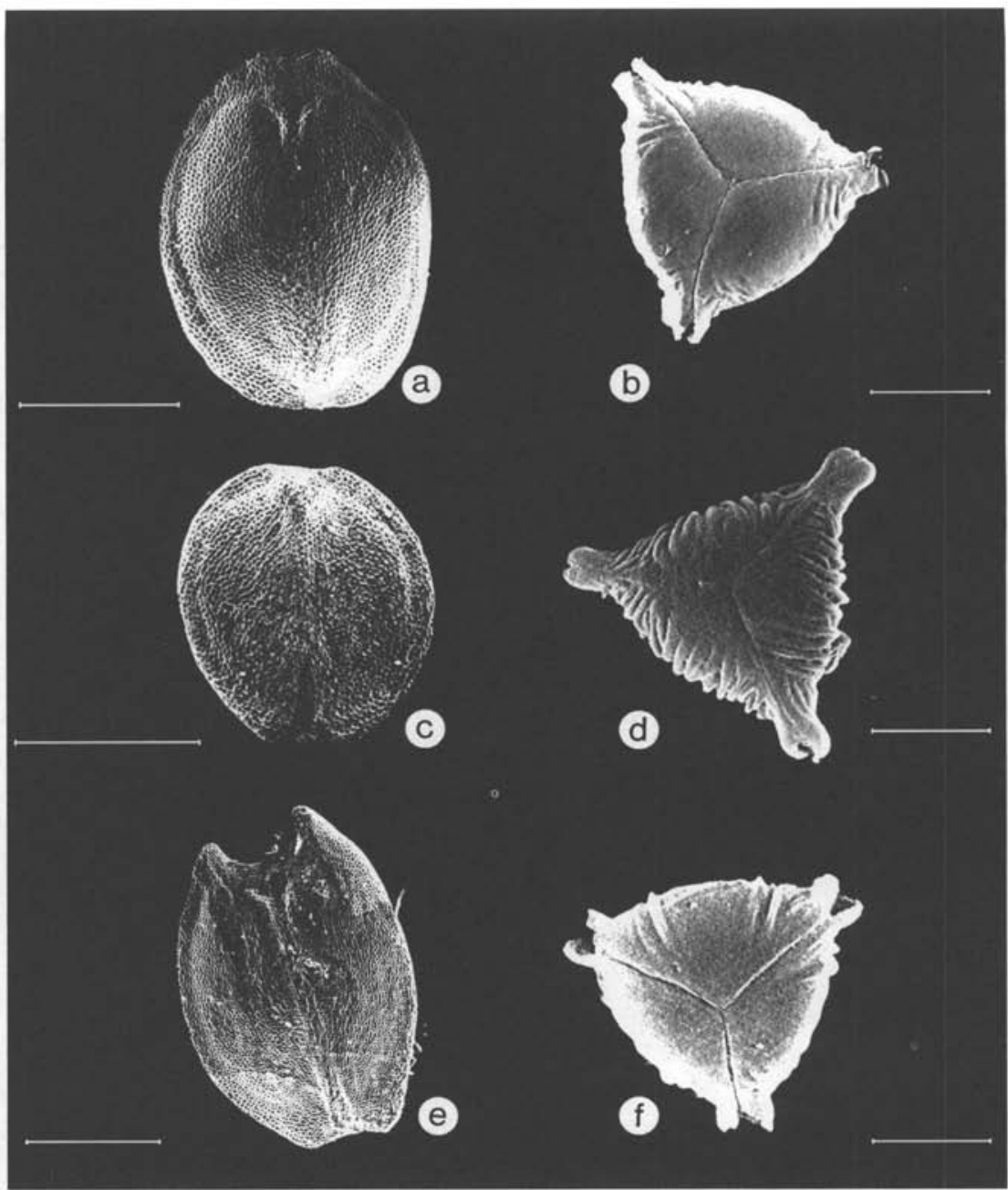

Figura 4. Sementes e pólen em Cuphea seção Brachyandra (MEV). a, b. C. elliptica (Lazor 2363, MO); c, d. C. parsonsia (semente: Ekman 872, S; pólen: Schafer 11666, NY); e, f. C. rusbyi (Rusby 117a, US). (Escalas: a, c, e $=1 \mathrm{~mm}$; b, d, $\mathrm{f}=10 \mu \mathrm{m}$ ).

0,52 e índice de retenção (ri) de 0,71. Embora o consenso estrito destas 370 árvores não seja bem resolvido, cinco espécies de Brachyandra formam um grupo monofilético [carthagenensis-spermacoce], que inclui duas espécies da seção Euandra (Fig. 7). Duas outras espécies da seção Brachyandra compartilham um ancestral comum com membros da seção Trispermum (ver clado micrantha-ericoides).

As sinapomorfias do clado são o pólen interaperturado de parede espessada e o ovário triovulado característico da seção Trispermum. Neste clado, em C. micrantha e C. tenuissima falta um dos caracteres tradicionalmente utilizado para definir a seção 


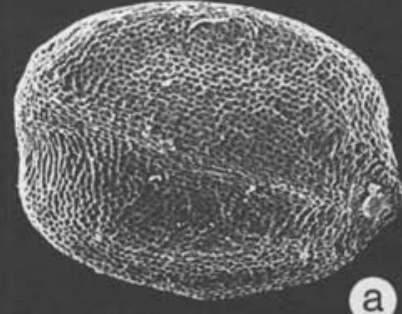

(a)

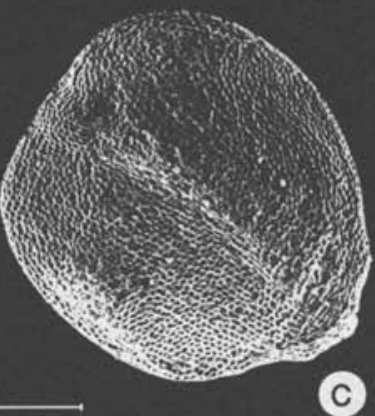

C

e)

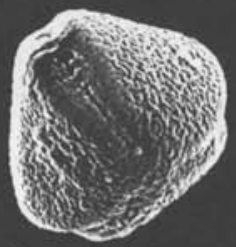

(b)

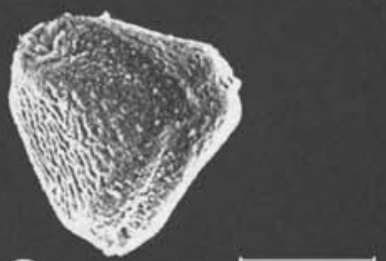

d

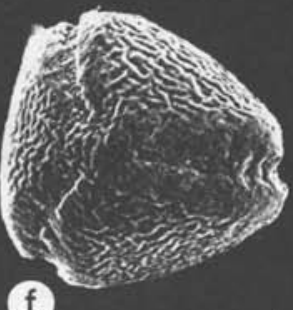

f

Figura 5. Sementes e pólen em Cuphea seção Brachyandra (MEV). a, b. C. calophylla (Nelson 5200, KEG); c, d. C. ciliata (Harling 6027, NY); e, f. C. circaeoides (Mori et al. 9967, NY). (Escalas: a, c, e = 1 mm; b, $d, f=10 \mu \mathrm{m})$. 


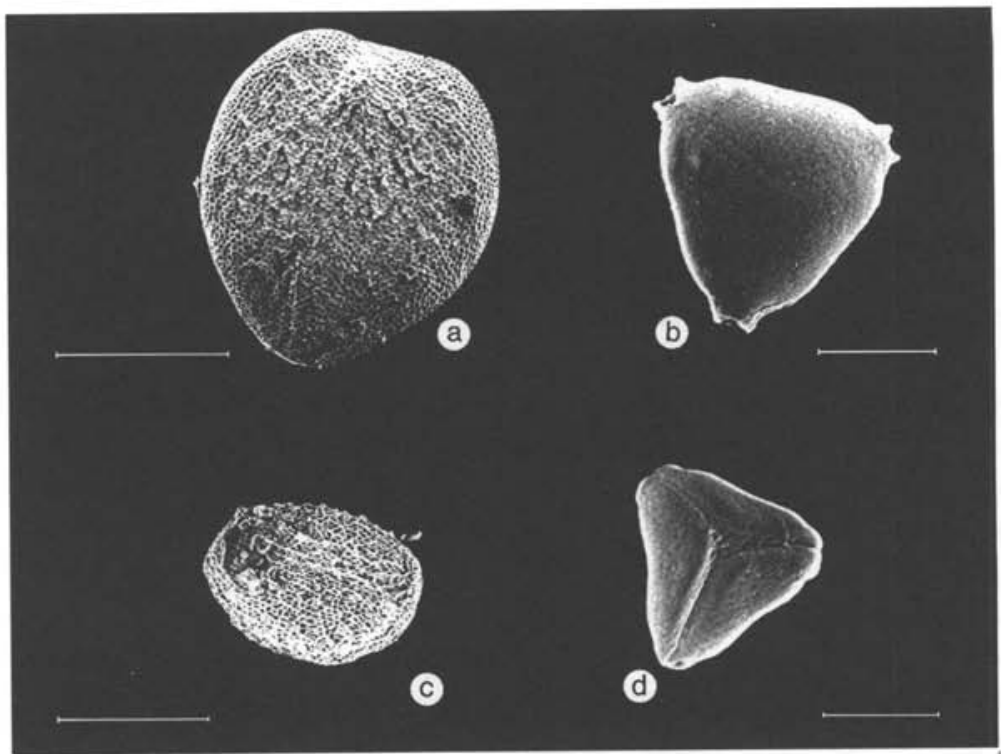

Figura 6. Sementes e pólen em Cuphea seção Brachyandra (MEV). a, b. C. micrantha (Irwin et al. 19080, NY); c, d. C. repens (Ferreira et al. $6078, \mathrm{NY}$ ). (Escalas: $\mathrm{a}, \mathrm{c}=1 \mathrm{~mm} ; \mathrm{b}, \mathrm{d}=10 \mu \mathrm{m}$ ).

Tabela 1: Lista de caracteres utilizados na análise cladística da seção Brachyandra.

1. Altura: $0=0,75 \mathrm{~m}$ ou mais; $1=$ menos do que $0,75 \mathrm{~m}$.

2. Hábito: $0=$ ereta; $1=$ decumbente a procumbente.

3. Tricomas malpiguiáceos: $0=$ ausência; $1=$ presença.

4. Pecíolos das folhas maiores: $0=2 \mathrm{~mm}$ ou mais; $1=$ menos do que $2 \mathrm{~mm}$.

5. Maior comprimento de folha: $0=40 \mathrm{~mm}$ ou mais; $1=$ menos do que $40 \mathrm{~mm}$.

6. Forma da folha: $0=$ oval, lanceolada ou elíptica; $1=$ linear.

7. Passagem do ramo vegetativo para a inflorescência: $0=$ gradual; $1=$ abrupta.

8. Posição da flor: $0=$ oposta; $1=$ alterna.

9. Inserção do pedicelo: $0=$ basal ou próximo à base; $1=$ ventral.

10. Comprimento do pedicelo: $0=0-4 \mathrm{~mm}$; 1 = maior do que $4 \mathrm{~mm}$.

11. Pedicelo: $0=$ com bractéolas; $1=$ com trichomas; $2=$ sem qualquer estrutura.

12. Cálcar: $0=$ ausente; $1=$ presente.

13. Apêndices (epicálice): $0=$ ausentes; $1=$ presentes, curtos e espessados; $2=$ presentes, pelo menos do comprimento das sépalas.

14. Pétalas: $0=$ caducas; $1=$ persistentes.

15. Número de estames: $0=11$ ou $12 ; 1=4-9$.

16. Pólen: $0=$ esferoidal, vista polar triangular; 1 = oblato, vista polar oval-triangular ; $2=$ oblato, vista polar triangular; 3 = prolato, vista polar variável entre arredondada e triangular.

17. Poros: $0=3 ; 1=2$.

18. Protusão do poro: $0=$ nenhuma. $1=$ distinta.

19. Colpo: 0 = não sincolpado; 1 - sincolpado.

20. Espessamentos interaperturados: $0=$ ausentes; $1=$ presentes.

21. Exina: $0=$ psilada a superficialmente rugulada; $1=$ estriada.

22. Diâmetro do pólen: $0=20 \mu \mathrm{m}$ ou menos; 1 = maior do que $20 \mu \mathrm{m}$.

23. Número de óvulos: $0=4$ ou mais; $1=3$.

24. Margem da semente: $0=$ espessa, arredondada; $1=$ delgada, alada.

25. Forma da semente: $0=$ orbicular a oblonga; $1=$ cordiforme.

26. Disco do ovário: $0=$ circular, em forma de taça; 1 = unilateral.

27. Disco do ovário: $0=$ em forma de taça ou horizontal a unilateral deflexo; $1=$ fortemente recurvado. 
Tahela 2: Matriz de dados para a análise cladística; $\mathrm{a}=0 \mathrm{e} 1$.

\begin{tabular}{|c|c|c|c|c|c|c|}
\hline \multicolumn{7}{|l|}{ Grupos externos: } \\
\hline Pleurophora & 00011 & 00100 & 00200 & 00000 & 01000 & 00 \\
\hline C. utriculosa & 10011 & 10001 & 20100 & 00000 & 00000 & 00 \\
\hline \multicolumn{7}{|l|}{ Grupo interno: } \\
\hline C. calophylla & 10011 & 01110 & 00100 & 00000 & 00000 & 10 \\
\hline C. carthagenensis & 10001 & 00110 & 01100 & 10110 & 11010 & 10 \\
\hline C. ciliata & 11011 & 00111 & 01100 & 00000 & 00000 & 10 \\
\hline C. circaeoides & 10000 & 01110 & 00100 & 00000 & $00 \mathrm{a} 00$ & 10 \\
\hline C. elliptica & 10010 & 00110 & 11101 & 10110 & 11010 & 10 \\
\hline C. ericoides & 10011 & 10110 & 01200 & 10011 & 01100 & 11 \\
\hline C. glutinosa & 11001 & 00110 & 01100 & 31000 & 01000 & 10 \\
\hline C. Myssopifolia & 10011 & 10110 & 01100 & 00000 & 00000 & 10 \\
\hline C. kubeorum & 11111 & 10110 & 01100 & 00000 & $00 \mathrm{a} 00$ & 10 \\
\hline C. linifolia & 10011 & 10111 & 01100 & 00000 & 00000 & 10 \\
\hline C. Iutescens & 00000 & 00111 & 11210 & 31000 & 01000 & 10 \\
\hline C. melanium & 11011 & 00110 & 00100 & 00000 & 00000 & 10 \\
\hline C. micrantha & 10010 & 00110 & 11100 & 10011 & 01101 & 10 \\
\hline C. parsonsia & 11011 & 00110 & 01101 & 10110 & 11010 & 10 \\
\hline C. pseudosilene & 11111 & 00111 & 01100 & 10110 & 11100 & 10 \\
\hline C. odonellii & 11111 & 10110 & 01200 & 00000 & 00a00 & 10 \\
\hline C. repens & 11111 & 10110 & 00100 & 20010 & 00000 & 10 \\
\hline C. riparia & 10011 & 00110 & 00100 & 00000 & 00000 & 10 \\
\hline C. rusbyi & 10010 & 10110 & 01100 & 10110 & 11010 & 10 \\
\hline C. sessiliffora & 10001 & 00110 & 01110 & 31000 & 01000 & 10 \\
\hline C. sessilifolia & 00011 & 00110 & 01100 & 10011 & 01100 & 11 \\
\hline C. spermacoce & 10010 & 00a11 & 01100 & 10110 & 11000 & 10 \\
\hline C. strigulosa & 10001 & 00110 & 01100 & 10110 & 11010 & 10 \\
\hline C. tenuissima & 10010 & 10110 & 01100 & $1001 \mathrm{a}$ & 01101 & 10 \\
\hline C. urens & 11001 & 00110 & 01100 & 00000 & 00000 & 10 \\
\hline
\end{tabular}

Trispermum, que é o disco nectarífero fortemente recurvado. As espécies da seção Trispermum ocorrem no Brasil oriental, nas restingas e montanhas do Nordeste, Sudeste e Centro-Oeste. Tal distribuição é coincidente com a de $C$. micrantha e parcialmente com a de C. tenuissima, restrita ao Centro-Oeste. Outra espécie da seção Brachyandra, C. repens, forma um grupo monofilético com espécies da seção Amazoniana (kubeorumodonellii-repens) compartilhando os seguintes caracteres: tricomas malpiguiáceos, pólen pequeno e psilado e hábito decumbente. Tal relacionamento é reforçado pelo fato destas espécies ocorrerem em terras baixas e úmidas da porção ocidental da América do Sul.

Os relacionamentos das seis espécies restantes de Brachyandra estão sem resolução, formando politomia nesta análise, junto com espécies da seção Cuphea ( $C$. utriculosa), Euandra (C. hyssopifolia, C. linifolia, C. glutinosa) e Pseudocircaea (C. sessilifolia, C. lutescens). 


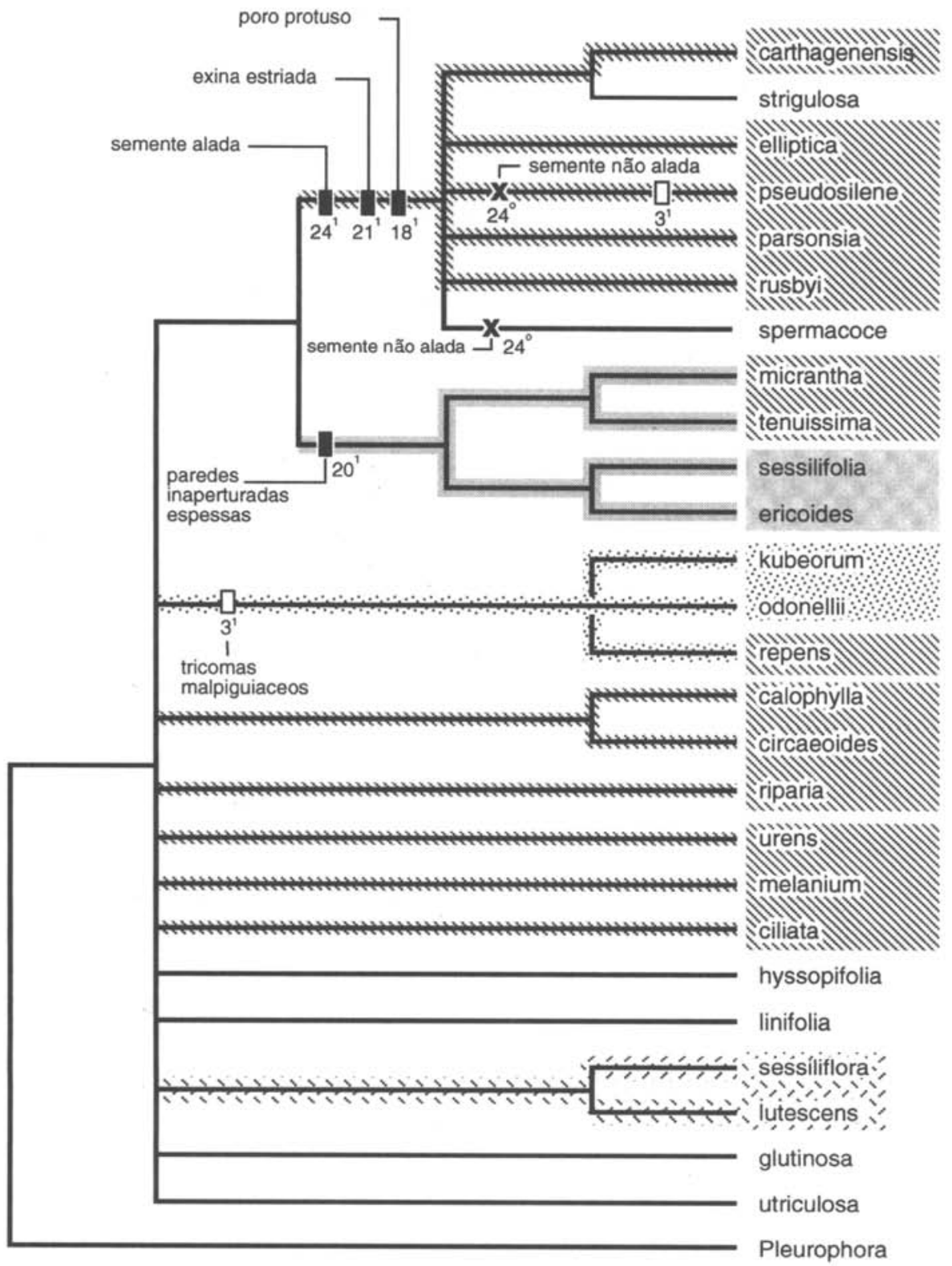

Figura 7. Cladograma de consenso estrito de 370 árvores $(\mathrm{CI}=0,52 ; \mathrm{RI}=0,71)$ mostrando alguns dos caracteres selecionados. Barra preta $=$ sinapomorphia única; barra branca $=$ homoplasia; $\mathrm{X}=$ reversão. seção Brachyandra $\mathbb{N}$; seção Trispermum $\quad$; seção Amazoniana ; seção Pseudocircaea :-:; seção Euandra $\square$. 
Os resultados indicam que os novos caracteres de semente e pólen são altamente informativos na sugestão de relacionamentos naturais. Dos 27 caracteres, 14 foram totalmente pesados na análise e, destes, nove são caracteres das sementes ou do pólen. Em análise cladística adicional, a pesagem sucessiva diminuiu o número de árvores para 11 mas não alteraram os relacionamentos resolvidos e nem proveram qualquer resolução adicional para aqueles não resolvidos. Em uma segunda rodada de pesos sucessivos, foram mantidas as 11 árvores. Depois de efetuar-se as pesagens sucessivas, os seguintes caracteres foram pesados em cinco ou menos, em uma escala de 1-10, contribuindo pouco para a resolução do cladograma: caracteres 1-6, 10-13 e 19 . Caracteres das sementes e pólen permaneceram altamente informativos. As poucas sinapomorfias que sustentavam as árvores mais bem resolvidas estão indicadas no cladograma de consenso (Fig. 7).

Como conclusões, pode-se colocar que a análise filogenética sugere que a seção Brachyandra é altamente artificial, reunindo espécies de pelo menos quatro diferentes fontes de ancestrais. Os caracteres florais que definem a seção, ou seja, tubos florais pequenos e estigma e anteras proximamente associados e profundamente inseridos no tubo floral, parecem ter aparecido repetidamente, do mesmo modo que as espécies autógamas evoluíram múltiplas vezes (experimentalmente verificado em $C$. carthagenensis, C. elliptica, C. parsonsia, C. micrantha, C. calophylla, C. melanium) de diferentes ancestrais alógamos. A hipótese de convergência tem mais suporte do que a de monofiletismo. Uma classificação do gênero, filogeneticamente estruturada, restabelecerá os limites seccionais de Brachyandra, ou mais provavelmente, descartará inteiramente a seção, ficando as espécies autógamas reclassificadas próximas de suas espécies alógamas filogeneticamente relacionadas.

\section{Agradecimentos}

Agradeço à Dr ${ }^{a}$ Taciana B. Cavalcanti, da EMBRAPA/CENARGEN, por traduzir este trabalho para o Português. Agradeço aos curadores dos herbários A, BM, CEN, FLAS, GH, K, MO, NY, SPF e US pelo empréstimo de espécimes e, especialmente, pelo empréstimo dos tipos das espécies estudadas. Ao Dr. Thomas Zanoni, que forneceu sementes de Cuphea urens e C. micrantha de Hispaniola, e a Alan Graham, que colaborou com a sua experiência no processamento do pólen e MEV. Esta pesquisa foi financiada pelo United States National Science Foundation, através da bolsa DEB 9509524 , concedida à autora.

\section{Referências bibliográficas}

Erdtman, G. 1960. The acetolysis method. A revised description. Svensk Botanisk Tidskrift 54: 561-564. Graham, S. 1999. Lythraceae. In: Kubitzki, K. (ed.), The Families and Genera of Vascular Plants. Vol. 3. Springer-Verlag, Berlin (in press).

Koehne, E. 1903. Lythraceae. In: Engler, A. (ed.). Das Pflanzenreich. IV. 216. Heft 17. Wilhelm Englemann, Leipzig.

Maddison. W. \& Maddison, D. 1992. MacClade. Vers. 3. Sinauer Assoc. Inc., Sunderland.

Swofford. D. L. 19993. PAUP, Vers. 3.1. Smithsonian Institution. Washington, DC.

Weberling. F. 1989. Morphology of flowers and inflorescences. Cambridge University Press, Cambridge. 